Mary M. Gaylord

\title{
La historia verdadera de la escritura en español en la Modernidad temprana: algunas reflexiones americanas
}

\author{
Traducción por María Piedad Quevedo Alvarado
}

Mary M. Gaylord es profesora del Departamento de Lenguas y Literaturas

Románicas de Harvard University. PhD en Español, Harvard

University. Correo electrónico: mgaylord@fas.harvard.edu

María Piedad Quevedo es Profesora del Departamento de Literatura

de la Pontificia Universidad Javeriana, Bogotá. PhD Lenguas y

Literaturas Románicas, Harvard University. Autora de Un cuerpo

para el espíritu. Mística en la Nueva Granada: el cuerpo, el gusto y el

asco. 1680-1750 (Instituto Colombiano de Antropología e Historia

ICANH, 2007). Correo electrónico: mquevedo@javeriana.edu.co

\footnotetext{
Ensayo

Publicado originalmente en inglés: "The True History of Early Modern Writing in Spanish: Some American Reflections". Modern Language Quarterly 57: 2 (1996): 213-225. Impreso.

Documento accesible en línea desde la siguiente dirección: http://revistas.javeriana.edu.co

doi: 10.11144/Javeriana.cl20-39.hvee
} 
LA ESCENA DE escritura de este ensayo es una caminata en la mañana a lo largo del río Charles ${ }^{1}$. Me abro paso entre calles estrechas y tomo el camino más cercano al agua, dejando al calor del momento la decisión de cruzar — cuándo, por cuál puente, incluso si. Desde el lado de Cambridge veo los edificios neo-georgianos de la escuela de negocios, copiados del campus antiguo, y trasplantados a la orilla opuesta en filas ordenadas y relucientes. Sé que hay "otro mundo" allí; con frecuencia vuelvo sobre mis pasos sin siquiera cruzar el río. No obstante, cuando sí sigo alguno de los puentes y me traslado al otro lado, miro atrás a "mi ciudad". Todos los días, menos los más tempestuosos, Cambridge es doblada por el río Charles, su horizonte se delinea dos veces, en mundos pares arriba y abajo, como los de un poema barroco. En los días soleados los viejos edificios se contemplan a sí mismos con satisfacción; en las mañanas nublosas, la ciudad sueña su rostro en el espejo del agua. Sospecho que se enfada cuando el viento los vuelve arrugados. Pero puedo ver el reflejo de la auto-imagen de mi ciudad solo cuando estoy en la otra orilla, cuando mi allá se ha vuelto un aquí, y mi antiguo aquí un allá. Mientras camino, trasladándome de una orilla en otra, me hallo en dos lugares a la vez.

Anécdotas como ésta entrañan grandes riesgos. No solo la autorreferencia indulgente ha sido un vehículo fácil para la ironía, sino que Cambridge, Massachusetts, y sus residentes se han asegurado un nicho,justo al lado de la madrastra de Blancanieves, en el hall de la fama de los auto-contempladores. Asumo los riesgos aquí, con alguna aprehensión, de forma que pueda usar la ruta de mi ejercicio como una parábola del itinerario en dos mundos de la escritura española durante los siglos XVI y XVII, particularmente la escritura de textos presentados como "historias verdaderas". Creo que la misma ruta también puede servir como una figura reveladora para los itinerarios de la crítica y de la historia literaria, es decir, para los caminos y cruces que han dado lugar a encuentros entre estudiosos de la literatura del siglo de oro y los de la literatura latinoamericana colonial desde los años 90 del siglo XX.

La deambulatio anima $e^{2}$ como figura de itinerarios mentales era familiar para los lectores del Siglo de Oro gracias al Examen de ingenios para las ciencias (1575), donde Juan Huarte de San Juan la usó para metaforizar las divagaciones de la más vagabunda de las facultades humanas, la imaginación o imaginativa ${ }^{3}$. El vínculo en-

1 N.T.: La autora se refiere al río que separa y une las ciudades de Boston y Cambridge, en el estado de Massachusetts, Estados Unidos.

2 N.T.: Cursivas en el original.

3 Ver Huarte de San Juan, Examen de ingenios para las ciencias. N.T.: Cursivas en el original. 
tre el movimiento físico y los procesos de la imaginación y el pensamiento se vuelve particularmente sugestivo en el mundo extremadamente móvil de las culturas de los siglos XVI y XVII ${ }^{4}$. Como la "compañera del imperio" de la famosa formulación del gramático Antonio de Nebrija, la lengua castellana produjo gran parte de su discurso y de su escritura sobre la marcha ${ }^{5}$. Muchos escritores hispánicos, como los cronistas de Indias, "vinieron a escribir" (en la maravillosa expresión de Hélène Cixous) literalmente en movimiento, ya fuese de ida, moviéndose entre los lugares que visitaban, o de regreso a casa. Una gran porción de la literatura canónica de lo que se ha venido a llamar Siglo de Oro español lleva, junto con la obsesión por lo temporal adscrita rutinariamente al barroco, la conspicua marca temática de la transitoriedad. Una serie de transeúntes literarios de los más celebrados del período viene de inmediato a la mente: soldados imperiales (dos Garcilasos de la Vega, Hernando de Acuña, Alonso de Ercilla, Miguel de Cervantes) y clérigos itinerantes (Bartolomé de las Casas, Juan de la Cruz, Teresa de Ávila); caballeros ficticios, pícaros, pastores, poetas-peregrinos como el de Góngora, errantes amantes bizantinos. Tampoco es sorprendente que la temática de la transitoriedad haya engendrado lo que puede llamarse una poética de la transgresión. La predilección del período por sobrepasar los límites clásicos es proverbial: la historia literaria nos ofrece el registro no de transgresiones aisladas, de eventos únicos, sino de múltiples cruces y recruces de fronteras que se vuelven a trazar continuamente y linajes literarios que se mezclan. Estos "siglos de oro" seguramente deben mucha de su deslumbrante riqueza tanto a los tránsitos literales de sus escritores como a sus transgresiones literarias, en suma, a la práctica cultural generalizada, real e imaginada, de las distancias y de la diferencia.

Ningún corpus de obras escritas en el mundo hispanohablante de la modernidad temprana ofrece evidencia más elocuente de esta transgresividad crónica que las que se agrupan bajo el nombre promisorio y sospechoso de historia verdadera ${ }^{6} \cdot{ }_{\mathrm{d}}$ Por qué será que esta rúbrica aparece en tantos textos y en una gama tan extraordinaria de situaciones y modos de escritura en español? Mi triple propósito es extraer de un topos familiar una explicación histórica nueva de esa fascinación por las capacidades de la narrativa que promete decir la verdad; sugerir que un compromiso con la historia, ya sea "seria" o ficcional, es necesariamente un compromiso con las dos modalidades; y proponer al Quijote como la summa de

4 Georges van den Abbeele en Travel as Metaphor: From Montaigne to Rousseau y Steven Hutchinson en Cervantine fourneys desarrollan la conexión entre movimiento literal y figurativo.

5 Ver Nebrija, Grammatica Castellana, 1492; El Orthografia Castellano, 1517.

6 N.T.: Cursivas en el original. 
esta doble obsesión de su época. Esta última propuesta implica dos afirmaciones poco convencionales que no puedo sustentar adecuadamente aquí pero que son indicadores esenciales de dónde viene y hacia dónde va mi meditación sobre la "historia verdadera" . Primero, leo el Quijote como un libro no solo sobre ficción y sobre la escritura de ficción, sino también sobre historia y sobre la historiografía seria de su época. Segundo, creo que su hechura novelesca está vinculada, no solo en un sentido general sino en formas textuales concretas, con la escritura historiográfica en español sobre el Nuevo Mundo. Si esto es cierto, la obra maestra de Cervantes pertenece tanto al discurso de "Latinoamérica colonial" como al del "Siglo de Oro" español.

La historia verdadera ${ }^{8}$, como un motivo itinerante, surge en una asombrosa variedad de textos. Predeciblemente, el nombre es aplicado a obras narrativas que hacen reclamos serios, responsables, incluso verosímiles, de veracidad. La Historia verdadera de la conquista de la Nueva España de Bernal Díaz del Castillo (titulada póstumamente para su publicación en 1632) es la más conocida, pero en el mundo hispánico de los años 1500 a 1700 su nombre era legión ${ }^{9}$. Sus temas abarcan desde España, Europa, el Mediterráneo, Levante, el Lejano Oriente y las Indias. Si acordamos poner entre paréntesis por un momento la distinción entre los términos historia y relación (la última reservada ordinariamente para narraciones más locales), podemos traer a este grupo de "historias factuales" el inmenso número de libros y pliegos sueltos que ofrecían recuentos de eventos históricos contemporáneos ${ }^{10}$. Muy otro es el tipo de "historia verdadera" que

7 Las reflexiones de este ensayo pertenecen a un libro en preparación. Uno de sus capítulos estudia el tropo narrativo de la historia verdadera en el Quijote de Cervantes, donde lo interpreto como reflejo de las numerosas variedades de la escritura historiográfica de la modernidad temprana en España.

8 N.T.: Cursivas en el original.

9 Ver Díaz del Castillo, Historia verdadera de la conquista de la Nueva España. Sumado a la famosa Historia verdadera del rey Don Rodrigo de Miguel de Luna (Granada, 1592, 1600), claramente fraudulenta, la colección de libros raros de la Biblioteca Houghton de Harvard alberga un grupo de textos históricos de los siglos XVI y XVII que se anuncian como "verdaderos", registrando viajes a Tierra Santa, batallas famosas, nacimientos y muertes de la realeza, el recibimiento de embajadores españoles en el extranjero, catástrofes naturales, apariciones de la Virgen María, y muchos otros. Aunque la etiqueta de relación verdadera es aplicada con mano liberal durante este período a mucha escritura documental de testigos presenciales, análogos en función al actual periodismo escrito y de televisión, el término historia verdadera es aplicado con menos frecuencia, y por lo tanto todavía habría sido un título provocativo para un trabajo a mayor escala de interpretación histórica.

10 Sobre las distinciones genéricas entre tipos de escritura histórica sobre América, ver Mignolo, "El metatexto historiográfico y la historiografía indiana". 
se encuentra en las más sospechosas narraciones que apuntan a la curiosidad del lector general y juegan con ella, recontando sucesos imaginarios que, de forma más o menos convincente, alegan haber ocurrido. En esta categoría van las seudocrónicas de emperadores romanos y del emperador Carlos V de Antonio de Guevara, los falsos cronicones, los Libros plúmbeos, y la Historia verdadera del Rey don Rodrigo, cuyo intérprete real Miguel de Luna afirmó haberla traducido de un original árabe del siglo VIII, registrado por un testigo presencial de la mítica escena de la "pérdida de España". Aunque su travieso intento hoy nos parece parece transparente, algunas de estas "historias verdaderas" fueron consideradas auténticas por muchas generaciones de lectores hasta entrado el siglo XIX, especialmente fuera de España ${ }^{11}$ —no obstante las protestas de Nicolás Antonio en el siglo XVIII- Un tercer grupo de textos que hace serios reclamos de verdad son las historias en verso, poemas épicos basados con más o menos firmeza en acontecimientos históricos que se sabía que habían tenido lugar. Entre ellos encontramos La Araucana de Ercilla (1569, 1578, 1589), la Austríada de Juan Rufo (1584), las Elegías de varones ilustres de Indias de Juan de Castellanos (1589), la Mexicana de Gabriel Lasso de la Vega (1594), y muchas más ${ }^{12}$. Finalmente llegamos a las "historias verdaderas" que todos los lectores toman por tales solo en el nombre: ficciones que, como Don Quijote, se basan en la empresa "historiográfica" de su autor y hacen de la "historia verdadera" la metáfora central para la construcción de una ficción narrativa ${ }^{13}$.

En la modernidad temprana, "historia verdadera" es tanto un amplio toldo como una rúbrica extraordinariamente proteica, desempeñado una variedad de papeles discursivos, introduciendo materias divergentes, moviéndose por múltiples cronologías y geografías. Su astuta etiqueta cubre todo desde el concepto epistemológico, hasta la estratagema publicitaria, la paradoja formal (por ejemplo, una historia compuesta en verso), hasta la figura pura. Visita los extensos espacios de lo que se ha llamado el cronotopo renacentista, balanceándose entre tiempos antiguos y modernos, atravesando los continentes y los océanos de una geografía post 1492, cruzando las fronteras de géneros clásicos y modernos, floreciendo en territorios liminares entre la realidad y la fantasía. Como un sello ubicuo, el término hizo todo salvo lo que ostensiblemente debía hacer: en palabras de Charlie

11 Un estudio clásico sobre las particularidades de la seudohistoriografía española del siglo XVI es "Don Quixote: Story or History?" de Bruce Wardropper.

12 El estudio canónico de Frank Pierce sobre la épica del siglo de oro, The Heroic Poem of the Golden Age, presenta evidencia de un asombroso número de ciento cincuenta poemas épicos escritos en español en el período de la modernidad temprana.

13 Esta teoría es adelantada por Wardropper (ver nota 11). 
Brown, la historia verdadera hizo cada vez más difícil distinguir las voces auténticas de las fraudulentas. La "historia verdadera" fue la gran travestista lingüística de la época: fue a todas partes travestida; su nombre ofrecía no una esencia sino un disfraz. Aun así, en tiempos de Cervantes la etiqueta historia verdadera vendió libros. Este hecho no lo acaban de explicar ni la credulidad ni la popularidad duradera de una buena broma. Como los de otras formas de travestismo, los caprichos de la "historia verdadera", incluso cuando está siendo parodiada, apuntan a una subyacente ansiedad cultural sobre la naturaleza de la verdad histórica y sobre la capacidad del lenguaje escrito de conocerla y transmitirla ${ }^{14}$.

Ya sea que se lo proponga o no, el sello "historia verdadera" abre una auténtica caja de Pandora que la simple "historia" había dejado sin tocar. Invocar una "historia verdadera" es a lo menos activar una dinámica de curiosidad. Asocia la historia con las acciones de descubrir, presenciar, registrar. Como la historia de una aventura cognitiva o epistemológica, la "historia verdadera" centra la atención sobre la escena de su escritura y sobre la posición de sujeto del historiador. Las "historias verdaderas" tienen siempre un argumento doble: son "historias de una historia", como Carmelo Sáenz de Santa María dice en otro sentido sobre el texto de Bernal Díaz ${ }^{15}$. Necesariamente recuentan dos historias: una, la historia de los eventos; la otra, la historia de cómo el autor llegó a saber lo que sabe y a escribirlo, es decir, cómo es que el texto histórico ha llegado a ser. Y como historias de una historia, las "historias verdaderas" ponen en tela de juicio, junto con la verosimilitud de personas, lugares y sucesos que detallan, el mismo privilegio autorial que invocan.

Con su progenie dispersa sobre vastas geografías reales y ficcionales, la historia textual de la historia verdadera se lee como un romance familiar de saber y escritura, en el curso del cual la autoridad de la representación circula entre historia y poesía, historia poética y ficción histórica, viejo y nuevo mundo, a menudo haciendo suyo más de un territorio. Muchas voces dan testimonio de las incomodidades e incertidumbres experimentadas por ese sospechoso linaje: teóricos de la ficción como Jacques Amyot, Torquato Tasso y Alonso López Pinciano aconsejan a aquellos contemporáneos suyos del siglo XVI que escriben romances, que se aparten de los mundos conocidos para ahorrarse las cavilaciones de los pedantes (Forcione 80). Pinciano concede (con resonancias de Borges) en la Philosophia Antigua Poética que sería posible para dos autores producir una y la misma relación escrita de un suceso y que una fuese histórica y la otra ficcional

14 Ver Garber, Vested lnterests: Cross-Dressing and Cultural Anxiety.

15 Ver Sáenz, Historia de una historia: la crónica de Bernal Díaz del Castillo. 
(Pinciano 2, 9-10). El lexicógrafo Sebastián de Covarrubias Orozco, lamentando en su Tesoro de la Lengua Castellana o Española de 1611 que las verdaderas hazañas españolas en el Nuevo Mundo eran tan fabulosas que no serían reconocidas por verdaderas por futuros lectores, especialmente extranjeros, legislaría que la historia debía ser escrita exclusivamente en prosa (Covarrubias 580 ).

Aquí y en otros casos, se nos recuerda insistentemente que la frontera que separa lo histórico de lo ficcional era todo menos clara. La representación, parecen decir estas voces, es tierra de nadie, donde es más fácil pasar de un campo al otro sin darse cuenta que trazar una línea divisoria entre ellos. Y es mucho más fácil para el escritor de ficción que su relato pase por historia, que para el más serio cronista de mundos poco conocidos limpiar su "historia verdadera" de la acusación de la mentira.

Muchos lectores han concluido que los trajinados binomios realidad y fantasía, hecho y ficción, historia y poesía, son o bien neo-aristotélicos, o "naturalmente" barrocos. Pero no fue solo el redescubrimiento humanístico de la Poética de Aristóteles lo que hizo de la verosimilitud y la maravilla las cuestiones candentes del momento ${ }^{16}$. Más bien, fue la vívida experiencia de nuevos mundos asombrosos y la urgente necesidad de escribir sobre ellos, tanto en Europa como en América, lo que hizo que el historiador más responsable y el fabulador literario remaran en la misma galera. De hecho, la mayoría de los escritores de la modernidad temprana, ya fuese de ficción o de historia, lucharon con el mismo ñudo de paradojas representacionales, pues ambos, después de todo, tenían que hacer presentes cosas "jamás vistas ni oídas" en el aquí y el ahora de la imaginación de sus lectores. Ambos debían tratar con cosas "no aquî": la ficción, con escenas y personajes que por definición no estaban aquí, que no existían ni existirían nunca por fuera de las páginas de los libros; la historia contemporánea, con escenas radicalmente nuevas, "no aquî", pues la distancia física dramáticamente incrementada impedía que se compartiese la experiencia. Pareciera que la distancia espacial del presente fuese mucho más inquietante que la distancia temporal del pasado remoto, quizá porque la extensión geográfica revelada recientemente no había sido aún abarcada por una cadena establecida de testigos autorizados, quizá también porque sus asombrosas realidades no podrían ser pensadas nunca como un allá seguro, escondido en un texto venerable, pues seguían revelándose y parecían invadir de modos inesperados la propia experiencia. El escritor que

16 Bernard Weinberg identifica la traducción latina de 1498 de Giorgio Valla como el primer paso importante en la reintroducción de la Poética en el pensamiento literario europeo (Weinberg 1,361). 
se proponía historiar lo desconocido debía establecer su propia cadena de testigos y documentos, $\mathrm{y}$ trabajar activamente para mantener su autoridad frente a la incredulidad de sus lectores, así como frente a la posible aparición de otros testigos con otras historias, o de accidentes que requerirían la reescritura de toda la narración. Esta ansiedad de transmisión movió al sevillano Fernando de Herrera, poeta e historiador de la gran victoria cristiana de 1571 sobre el Islam en el Mediterráneo oriental, a desarmar a posibles críticos de su relación de la batalla de Lepanto pidiéndoles considerar "cuán incierta es la voz de la verdad, traída de partes tan remotas y de lenguas tan varias" (Herrera 248).

Mientras los escritores luchaban con la pregunta de cómo distinguir la "historia verdadera" de la fábula poética, Pinciano y Covarrubias vinieron muy cerca del reconocimiento moderno de que la diferencia entre las narrativas histórica y ficcional radica no en una esencia formal capaz de separar ovejas reales de cabras imaginarias, sino en un conjunto de acuerdos convencionales que gobiernan la relación del lenguaje con el mundo en cada género de escritura ${ }^{17}$. La representación histórica con frecuencia se fundamenta sobre aquello que ya ha sido reconocido como un hecho; en muchos casos, relata lo ya relatado. Trabajando sin el beneficio de relaciones previas, los primeros historiadores españoles del Nuevo Mundo tuvieron que construir las convenciones de lo real y lo verdadero desde la base de una experiencia inédita. Sus escritos testifican sobre todo la obsesión con la fundamentación en el mundo, que es esencial a la historia. Con todo, a medida que su empresa centra su atención en los modos en que la autoridad representacional es construida, inevitablemente pone en cuestión esa misma autoridad.

Se necesitó el genio de Cervantes para ver en la historia de la historiografía tanto la huella de la producción de ficciones como un profundo y problemático espejo de la angustia más apremiante de su cultura. En las búsquedas de sus autores personificados y de su envanecido protagonista por escribir lo real, por escribir la

17 Algunas contribuciones centrales para esta discusión en la actualidad son: Barthes, Roland. "The Discourse of History" y "The Reality Effect"; De Certeau, Michel. The Writing of History; Herrnstein Smith, Barbara. On the Margins of Discourse: The Relation of Literature to Language; y White, Hayden. Metahistory: The Historical Imagination in Nineteenth-Century Europe. [N.T.: hay edición en español: Barthes, Roland. "El discurso de la historia" y "El efecto de realidad". El susurro del lenguaje. Trad. C. Fernández Medrano, Barcelona: Paidós, 1987. Impreso; De Certeau, Michel. La escritura de la historia. Trad.Jorge López Moctezuma. México: Universidad Iberoamericana, 1993. Impreso; Herrnstein Smith, Barbara. Al margen del discurso: la relación de la literatura con el lenguaje. Trad. Elena Elorriaga. Madrid: Visor, 1993. Impreso; White, Hayden. Metahistoria: la imaginación histórica en la Europa del siglo XIX. Trad. Stella Mastrangelo. México: Fondo de Cultura Económica, 1992. Impreso]. 
"historia verdadera" del yo español y de sus otros, Cervantes resume los triunfos y los peligros de la gran aventura cognitiva de su tiempo y su sobredeterminada agenda política. Sin duda, Cervantes aprendió bastante de Luciano de Samósata acerca de las paradojas de la historia. Este autor griego del siglo II, mejor conocido por sus sátiras, produjo dos meditaciones historiográficas, una seria (Cómo escribir Historia) y una burlesca (Una historia verdadera), manuales de cómo sí y cómo no escribirla, que gozaron de enorme popularidad a través de traducciones y de la imitación de que fueron objeto durante el Renacimiento. Después de abrir la Vera historia con la provocativa declaración de que esta no contendrá ni una onza de verdad, Luciano despliega todo el arsenal de dispositivos historiográficos convencionales: autorreferencias a la primera persona que es testigo, detalles geográficos, descripción física, incluso "certificaciones notariales" de testigos de su paso por ciertos lugares. En el episodio culminante de su viaje, obtiene de una autoridad, nada menos que la de Homero, un poema que "certifica" su punto de encuentro y deja su marca en un árbol real. ${ }^{18}$ Cervantes incorpora muchos de estos mismos trucos, en gran medida a través de figuras autoriales sustitutas como la de Cide Hamete Benengeli y el "segundo autor". La última táctica se usa en el episodio en el que la novela roza más conspicuamente la realidad histórica: el relato intercalado del Capitán cautivo, cuya exactitud es finalmente validada no a través de documentos históricos sino por un par de sonetos, y cuyo narrador testigo evoca una figura fantasmal que invita al lector a asociarla ("un tal Saavedra") con el histórico Miguel de Cervantes Saavedra (Cervantes 1,486). En La Araucana, Ercilla también apropia el motivo lucianesco de escribir sobre las cortezas de los árboles para certificar su presencia en los lugares de Suramérica que describe (Ercilla 942-943).

El juego lucianesco con la verdad histórica fue la forma de convertir una fuente de ansiedad - cómo conocer la verdad real sobre los territorios recientemente descubiertos, cómo calibrar el valor de verdad de las relaciones contemporáneas, cómo hablar y escribir de forma creíble sobre el mundo- en regocijo. Con un ingenio perverso teñido de melancolía cultural, Cervantes aborda estas cuestiones dotando a sus personajes así como a su ficcional figura autorial de una obsesión historiográfica sobre la verdad de sus historias y, más aún, dejándolos contar sus

18 Ver Luciano de Samósata, "A True Story" y "How to Write History". El episodio del grabado en el árbol se encuentra en "A True Story" 333. Para las fortunas de Luciano en España e Italia durante este período, ver el exhaustivo trabajo de Michael O. Zappala, Lucian of Samosata in the Two Hesperias: An Essay in Literature and Cultural Translation. [N.T.: hay edición en español de Luciano de Samósata. "Relatos verídicos". Obras. Volumen 1. Madrid: Gredos, 1981. 176-227. Impreso, y "Cómo debe escribirse la historia". Obras. Volumen 3. Trad. Juan Botella Zaragoza. Madrid: Gredos, 1990. 367-408. Impreso]. 
historias con palabras sacadas de las obras de verdaderos historiadores, algunos de ellos conquistadores del Nuevo Mundo ${ }^{19}$.

En las fusiones y confusiones textuales de mundos históricos y ficcionales bajo el nombre de "historia verdadera" - en textos (Don Quijote y las crónicas del Nuevo Mundo) que se han leído como emblemáticos de su momento cultural- yace una importante lección para nosotros como críticos. Hasta muy recientemente, el mapa disciplinario sobre el cual están localizados los estudios de la modernidad temprana peninsular y americana se ha visto como una fórmula para distribuir el territorio textual de la poesía y la historia. Hemos llamado a una provincia "Siglo de Oro" dando por sentado que le concierne sobre todo la literatura, el arte por el arte, literatura salida de literatura, ficción sobre la ficción, la imaginación peligrosamente divorciada de una realidad que se desmorona. A la otra provincia, apodada "Latinoamérica colonial" le ha sido asignada la historia. En efecto, tanto en el lado europeo como en el americano, los intereses nacionales han favorecido principalmente la lectura patriótica de textos coloniales como documentos, ya sea de hazañas imperiales o de los nuevos orígenes nacionales, aunque sea mínima su conexión con el récord histórico. A los críticos nos ha sido difícil habitar simultáneamente dos mundos tan aparentemente diferentes; la mayoría han permanecido centrados en solo uno de ellos.

Pero la "verdad" sobre nuestra visión histórico-literaria es que hemos trazado un mapa que oscurece tanto como revela. Muchos son los textos que han estado temporalmente perdidos a las comodidades del provincialismo académico. Textos que abarcan dos hemisferios y dos (o más) culturas, como textos que intentan ubicarse en más de un género (algunos hacen todo lo anterior), tienden a caer entre los intersticios de esos órdenes, y por eso a ser tenidos por irrelevantes o imperfectos en relación con las categorías y normas establecidas. Incluso la extraordinaria Araucana de Ercilla no es hasta ahora una lectura corriente en los cursos de poesía del Siglo de Oro, que tradicionalmente han preferido enfocarse en la lírica, dejando la política y la historia a la prosa $-\mathrm{o}$ a los colonialistas. Una primera y obvia respuesta, a fines del siglo $\mathrm{XX}$, a las predominantes "políticas del centro" de ambos campos ha sido sintonizar nuestros oídos a las voces de la modernidad temprana que se emiten desde los márgenes del mundo hispánico, tanto peninsular como americano. En España, este enfoque descentrado, con raíces en el trabajo sobre los heterodoxos de Marcelino Menéndez y Pelayo y

19 Una de las tesis centrales de mi libro en progreso es que Cervantes puso las palabras de primera y segunda mano de Colón, Cortés, Las Casas y otros en las bocas de sus personajes, principalmente don Quijote y Sancho Panza. 
en la celebración de la diversidad cultural de los siglos formativos de la España moderna de Américo Castro, significa atender a la escritura "más allá de la literatura", como los testimonios inquisitoriales de los conversos de origen judío y musulmán, o los diarios de monjas ${ }^{20}$. Para los colonialistas, el descentramiento de años recientes ha significado empujar los linderos más allá de las copias barrocas de la colonia hacia espacios inexplorados allende los límites de las comunidades de lenguas románicas, e incluso más allá de la cultura europea del libro, para entrar en territorios anteriormente reservados a los antropólogos ${ }^{21}$.

Sin embargo, si es cierto que en este período las transgresiones eran una forma de vida literaria, incluso en obras escritas en el centro del centro de la cultura dominante, entonces nos urge releer la totalidad de aquello que estamos acostumbrados a pensar como el canon literario del Siglo de Oro, buscando las huellas de los cruces literales y figurativos que la doble naturaleza del mundo hispánico hizo inevitables. Cada cultura se sueña a sí misma en el espejo de sus ficciones. Géneros como el caballeresco, la pastoril, la picaresca, la épica, la lírica y la comedia dramatizaron la comprensión y la imagen ideal que los españoles hicieron de sí mismos, pues estaban obligados a localizarse en el mapa de un mundo transformado por la expansión territorial. Si queremos comprender el profundo impacto que el descubrimiento y la colonización tuvieron en la conciencia hispánica, no es suficiente mirar lo que los españoles escribieron sobre el Nuevo Mundo y sus habitantes; nos urge preguntar cómo cambió la imagen de sí mismos de los europeos en consecuencia de sus nuevos horizontes transatlánticos ${ }^{22}$. Como estudiosos de la literatura, debemos

20 Ver Menéndez y Pelayo, Historia de los heterodoxos españoles; y Castro, De la edad conflictiva: crisis de la cultura española en el siglo XVII. Sobre las voces de las mujeres y las monjas, ver Untold Sisters: Hispanic Nuns in their Own Works; El Saffar, Ruth Anthony. Rapture Encaged: The Suppression of the Feminine in Western Culture; Kagan, Richard L. Lucrecia's Dreams: Politics and Prophecy in Sixteenth-Century Spain; y Weber, Alison. Teresa of Avila and the Rhetoric of Femininity. [N.T.: hay edición en español de Kagan, Richard L. Los sueños de Lucrecia: política y profecía en la España del siglo XVI. Trad. Francisco Carpio. Madrid: Nerea, 1991. Impreso].

21 Importantes contribuciones a este trabajo son Adorno, Rolena K. Guaman Poma: Writing and Resistance in Colonial Peru; Harrison, Regina. Signs, Songs, and Memory in the Andes: Translating Quechua Language and Culture; López-Baralt, Mercedes. Icono y conquista: Guamán Poma de Ayala; Writing without Words: Alternative Literacies in Mesoamerica and the Andes; y Mignolo, The Darker Side of the Renaissance: Literacy, Territoriality, and Colonization. [N.T.: hay edición en español de: Adorno, Rolena. Guaman Poma: Literatura de resistencia en el Perú colonial. Trad. Martín Mur U. México: Siglo XXI, 1991. Impreso; Harrison, Regina. Signos, cantos y memoria en los Andes: traduciendo la lengua y la cultura quechua. Quito/Cayambe: Abya Yala, 1994. Impreso; Mignolo, Walter D. El lado más oscuro del renacimiento: literatura, territorialidad y colonización. Trad. Cristóbal Gnecco. Popayán: Universidad del Cauca, 2015. En prensa].

22 J. H. Elliott, en un estudio clásico, lo ha llamado "el incierto impacto" (Elliot 1-27). Yo creo que el impacto es muy cierto, si bien largamente inexplorado. [N.T.: hay edición en español: 
preguntarnos qué podemos aprender sobre el trabajo cultural encarnado en los géneros y las obras maestras del canon español cuando los miramos desde el otro lado. Todos los textos del Siglo de Oro, después de todo, fueron escritos no, como el término podría dar a entender, en algún "tiempo antes del tiempo" sino después de los viajes de Colón, y en gran parte después de la marcha de Tenochtitlán. El sentido común sugiere que estas obras, como espejos de una realidad histórica, no pueden no haber reflejado los horizontes recientemente expandidos y doblados de los mundos de sus autores.

Ya sea que escojamos permanecer centrados en el Viejo Mundo o en América, o que tratemos de abarcar uno y otro mundo, sí debemos reconocer que aquí y allá son deícticos particularmente resbaladizos para el período que estudiamos. Literalmente, tanto como en sus "paseos del alma", los sujetos hispánicos de los siglos XVI y XVII cruzaron muchos puentes, y en ambas direcciones ${ }^{23}$. El emblema más elocuente de este itinerario bidireccional en Cervantes es quizá el Clavileño, corcel de la Imaginación, que nos lleva un día a Francia, otro día a Potosí (Cervantes 2, 341). Si yo fuese un astronauta, mi emblema podrían ser las imágenes fotográficas de nuestro planeta sacadas en la primera expedición a la luna, imágenes que alteraron irrevocablemente la forma en que vemos el mundo. Pero como investigadora pedestre, hago mío el tropo cotidiano de la vista desde el otro lado del río, la vista que solo se puede tener una vez se ha cruzado al otro lado. Es el lugar desde el que se puede ver no solo el propio mundo sino el modo en que este se refleja a $(\mathrm{y}$ reflexiona sobre) sí mismo, el lugar desde el que se puede ver el propio mundo y a sí mismo "de otro modo", y en el que es probable que se sea "alterado" por ese reconocimiento. Cualquier futura "historia verdadera" de la escritura en español en la modernidad temprana tendrá que asumir esa doble imagen.

\section{Obras citadas}

Adorno, Rolena K. Guaman Poma: Writing and Resistance in Colonial Peru. Austin: University of Texas Press, 1986. Impreso.

Barthes, Roland. "The Discourse of History" y "The Reality Effect". The Rustle of Language. Trad. Richard Howard. Berkeley: University of California Press, 1989. 127-140 y 141-154. Impreso.

Castro, Américo. De la edad conflictiva: crisis de la cultura española en el siglo XVII. 4a. ed. Madrid: Taurus, 1976. Impreso.

Elliott, J. H. El viejo y el nuevo mundo 1492-1650. Trad. Rafael Sánchez Mantero. Madrid: Alianza, 1972. Impreso].

23 Ver Femández, "The Bonds of Patrimony: Cervantes and the New World". 
Cervantes, Miguel de. El ingenioso hidalgo don Quijote de la Mancha. Ed. Luis Andrés Murillo. 3 vols. Madrid: Castalia, 1978. Impreso.

Covarrubias Orozco, Sebastián de. Tesoro de la Lengua Castellana o Española. Facsímil. Madrid: Turner, 1979. Impreso.

De Certeau, Michel. The Writing of History. Trad. Tom Conley. Nueva York: Columbia University Press, 1988. Impreso.

Díaz del Castillo, Bernal. Historia verdadera de la conquista de la Nueva España. Ed. Miguel León-Portilla. 2 vols. Madrid: Historia 16, 1984. Impreso.

Elliott, J. H. The Old World and The New, 1492 - 1650. Cambridge: Cambridge

University Press, 1970. Impreso.

El Saffar, Ruth Anthony. Rapture Encaged: The Suppression of the Feminine in Western Culture. Londres: Routledge, 1994. Impreso.

Ercilla, Alonso de. La Araucana. Ed. lsaías Lerner. Madrid: Cátedra, 1993. Impreso.

Fernández, James D. "The Bonds of Patrimony: Cervantes and the New World", PMLA 109 (1994): 969-981. Impreso.

Forcione, Alban K. Cervantes, Aristotle, and the Persiles. Princeton, NJ: Princeton University Press, 1970. Impreso.

Garber, Marjorie. Vested lnterests: Cross-Dressing and Cultural Anxiety. Nueva York: Routledge, 1992. Impreso.

Harrison, Regina. Signs, Songs, and Memory in the Andes: Translating Quechua Language and Culture. Austin: University of Texas Press, 1989. Impreso.

Herrera, Fernando de. Relación de la guerra de Chipre y Suceso de la batalla naval de Lepanto: colección de documentos inéditos para la historia de España. Madrid: Sociedad de Bibliófilos Andaluces, 1852. Impreso.

Herrnstein Smith, Barbara. On the Margins of Discourse: The Relation of Literature to Language. Chicago: University of Chicago Press, 1978. Impreso.

Huarte de San Juan, Juan. Examen de ingenios para las ciencias. Ed. Esteban Torre. Madrid: Editora Nacional, 1976. Impreso.

Hutchinson, Steven. Cervantine fourneys. Madison: University of Wisconsin Press, 1992.

Kagan, Richard L. Lucrecia's Dreams: Politics and Prophecy in Sixteenth-Century Spain. Berkeley: University of California Press, 1990. Impreso.

López-Baralt, Mercedes. Icono y conquista: Guamán Poma de Ayala. Madrid: Hiperión, 1988. Impreso.

Luciano de Samósata. "A True History". Trad. A. M. Harmon. Lucian I. Loeb Classical Library. Cambridge, MA: Harvard University Press, 1913. 248-357. Impreso. "How to Write History". Trad. K. Kilburn. Lucian VI. Loeb Classical Library. Cambridge, MA: Harvard University Press, 1959. 2-73. Impreso. 
Menéndez y Pelayo, Marcelino. Historia de los heterodoxos españoles. 3 vols. Madrid: Librería Católica de San José, 1880. Impreso.

Mignolo, Walter D. "El metatexto historiográfico y la historiografía indiana". $M L \mathcal{N} 96$ (1981): 358-402. Impreso.

The Darker Side of the Renaissance: Literacy, Territoriality, and Colonization. Ann Arbor: University of Michigan Press, 1995. Impreso.

Nebrija, Antonio. Grammatica Castellana, 1492; El Orthografia Castellano, 1517.

Facsímil. Yorkshire: Scolar, 1969. a. ii. Impreso.

Pinciano. Philosophia Antigua Poética. Ed. Alfredo Carballo Picazo. 3 vols. Madrid: Consejo Superior de Investigaciones Científicas, 1973. Impreso.

Pierce, Frank. The Heroic Poem of the Golden Age. Oxford: Oxford University Press, 1947. Impreso.

Sáenz de Santa María, Carmelo. Historia de una historia: la crónica de Bernal Díaz del Castillo. Madrid: Consejo Superior de Investigaciones Científicas, 1984. Impreso.

Untold Sisters: Hispanic Nuns in their Own Works, Eds. Electa Arenal y Stacey Schlau. Trad. Amanda Powell. Albuquerque: University of New Mexico Press, 1989. Impreso.

Van den Abbeele, Georges. Travel as Metaphor: From Montaigne to Rousseau. Minneapolis: University of Minnesota Press, 1992. Impreso.

Wardropper, Bruce. "Don Quixote: Story or History?". Modern Philology 63 (1965): 1-11. Impreso.

Weber, Alison. Teresa of Avila and the Rhetoric of Femininity. Princeton, NJ: Princeton University Press, 1990. Impreso

Weinberg, Bernard. A History of Literary Criticism in the Italian Renaissance. 2 vols. Chicago: University of Chicago Press, 1961. Impreso.

White, Hayden. Metahistory: The Historical Imagination in Nineteenth-Century Europe. Baltimore, MD.: Johns Hopkins University Press, 1973. Impreso.

Writing without Words: Alternative Literacies in Mesoamerica and the Andes. Eds. Elizabeth Hill Boone y Walter D. Mignolo. Durham, NC: Duke University Press, 1994. Impreso.

Zappala, Michael O. Lucian of Samosata in the Two Hesperias: An Essay in Literature and Cultural Translation. Potomac, MD: Scripta Humanistica, 199o. Impreso. 